\title{
O entre-lugar da ex-apropriação: despossessão e propriedade nas escrituras falsas de Gloria Alzáldua e Édouard Glissant
}

\author{
Luis Felipe Silveira de Abreu*
}

Resumo

Este ensaio começa em um sinal: o hífen interposto por Jacques Derrida (2016) na grafia de ex-apropriação. Este quaseconceito opera demonstrando o paradoxo de propriedade existente no exercício da linguagem transcultural. Partindo da aporia que movimenta aquele ensaio, movimentamos nossa pesquisa a respeito de práticas de apropriação, cópia e imitação em textualidades contemporâneas. Neste texto, de caráter conceitual e exploratório, propomos um estudo da exapropriação como lógica dessas (re)escrituras. Na fulguração de seu hífen, buscamos entender a indecidibilidade desse lugar de fala transnacional também com a ideia entre-lugar, conforme elaborada por Silviano Santiago (2019). De forma a interrogar de modo localizado essa problemática, entendendo que ela só se dá na escritura, apresentamos e debatemos duas experiências desse entre. Primeiro, o texto de Gloria Anzáldua em seu Borderlands/La frontera (1987), livro escrito em um inglês atravessado pelos dialetos da fronteira mexicana, discutindo a vivência do migrante. De modo semelhante, acionamos também as poéticas de Édouard Glissant (2005): seus estudos sobre como o regime econômico de escambos no Caribe cria uma cultura de trocas precárias, origem das línguas crioulas. Na leitura dos signos que emitem essas línguas bífidas, o ensaio vai concluir pela produtividade de se enfocar o problema dos textos e trânsitos pós-nacionais pelo viés proprietário.

\footnotetext{
Universidade Federal do Rio Grande do Sul (UFRGS). Doutorando no Programa de Pós-Graduação em Comunicação (PPGCOM) da UFRGS. Membro do Grupos de Pesquisa em Semiótica e Culturas da Comunicação (GPESC). https://orcid. org/0000-0002-2460-5165.
} 
Infere-se como as noções de ex-apropriação e entre-lugar suscitam esse aspecto e permitem ler textos poéticos transculturais por tal chave - levando a uma compreensão da apropriação e da imitação como movimentos de um roubo que escancara a precária performance da posse.

Palavras-chave: Ex-apropriação. Entre-lugar. Propriedade. Jacques Derrida. Silviano Santiago.

\title{
The in-between of the ex-appropriation: dispossession and property in false scriptures
}

\begin{abstract}
This essay begins in a punctuation mark; the hyphen put by Jacques Derrida in the spelling of ex-appropriation. The quasiconcept of ex-appropriation operates by demonstrating the paradox of ownership that exists in the exercise of cross-cultural language. Starting from the aporia that moves that essay, we move our research on practices of appropriation, copying and imitation in contemporary textualities. In this text, conceptual and exploratory, we propose a study of ex-appropriation as the logic of these (re)scriptures. In the glow of its hyphen, we seek to understand the undecidability of this transnational place of speech also with the idea of the in-between, as elaborated by Silviano Santiago. In order to question this problem in a localized way, understanding that it only occurs in scripture, we start by presenting and debating two experiences of this between First, the Gloria Anzáldua's Borderlands/La Frontera, a book written in English crossed by Mexican border dialects, discussing the migrant's experience. Similarly, we also call the poetics of Édouard Glissant (2005): his studies on how the economic regime of barter in the Caribbean creates a culture of precarious exchange, origin of Creole languages. By reading the
\end{abstract}


signs emitted by these bifid languages, the essay will conclude the productivity of focusing on the problem of postnational texts and transits by the proprietary bias. It is inferred how the notions of ex-apropriation and in-between raise this aspect, and allow reading cross-cultural poetic texts by such a key leading to an understanding of appropriation and imitation as movements of a robbery that opens the precarious performance of possession.

Keywords: Ex-appropriation. In-Between. Property. Jacques Derrida. Silviano Santiago.

Recebido em: 17/03/2021 // Aceito em: 27/11/2021. 


\section{Introdução}

É preciso começar, até antes do começo, admitindo que nossa preocupação é com um hífen.

No mínimo desse sinal gráfico, mesmo que tão breve, é que localizamos a violência - e, a partir dela, uma possibilidade de se pensar sobre a escritura. Que hífen é esse? Aquele interposto por Jacques Derrida ao falar da ex-apropriação. O termo que aparece em $\mathbf{O}$ monolinguismo do outro (DERRIDA, 2016) diz da operação da escrita por aquele que vive entre línguas: ideias depreendidas da própria vivência de Derrida, nascido na Argélia sob domínio francês. Esse conceito, potente para pensarmos os problemas das poéticas de internacionalização, ao se ver atravessado pela lança desse hífen, coloca a questão da apropriação do alheio (daquele estrangeiro que não bem o é, na medida que também é próprio) em certa indecidibilidade. É uma expropriação que não se completa de todo e que se realiza de modo protético. Não se completa de todo, pois diz respeito a uma propriedade impossível no campo da linguagem.

A partir desse argumento é que partimos, que desfiamos as linhas das próximas páginas. E tentando entender esse hífen é que nos vemos levamos a puxar outro, aquele colocado no entrelugar proposto por Silviano Santiago (2019). O termo, nascido em célebre ensaio, acaba por nos auxiliar a entender o estranho espaço que a apropriação ocupa nessa poética de trânsito nacional entre línguas, bem como os modos pelos quais pode operar aí. Ex-apropriar é, entendido dentro do pensamento do entre-lugar, a criação de escrituras-falsas de propriedade (SANTIAGO, 1989), argumentamos. 
Por fim, o artigo joga essa rede de conceitos sobre algumas poéticas, algumas dessas escrituras-falsas, para compreender a operação literária da ex-apropriação. Entre a prosa bífida de Gloria Anzáldua (1987) e a poética crioula de Édouard Glissant (2000; 2005) vemos emergirem possibilidades de inscrição da experiência despossuída.

\section{Da ex-propriação: despossessão, tomada de posse e de volta outra vez}

"O que eu tenho dificuldade em entender é todo este léxico do ter, do hábito, da posse de uma língua que seria ou não a sua, a tua, por exemplo. Como se o pronome e o adjetivo possessivos fossem aqui, quanto à língua, proscritos pela língua [...]" (DERRIDA, 2016, p. 49). Lá pelo meio do diálogo, forma expositiva em que Derrida redige seu $\mathbf{O}$ monolinguismo do outro (2016), a voz anônima de seu interlocutor tece a dúvida acima - mas por que desse malabarismo com o vocabulário judicial-econômico da posse para tratar tão simplesmente do falar?

Tal dúvida se encontra no coração das preocupações desse breve livro, escrito tanto como exploração teórica quanto diário de memórias, escritos nascidos das rememorações do crescer na Argélia, do ser um francês africano, de aprender e falar a língua da metrópole na colônia. Essa tensão se constrói pela justaposição de dois postulados simultâneos: "não falo senão uma única língua, que não é minha" e "não se fala nunca apenas uma única língua”.

É um jogo tensivo e paradoxal, que coloca o lugar da enunciação em um espaço de indecisão. O franco-magrebino 
percebe que não pode senão falar o francês, ainda que este seja a língua de um outro, muito além das fronteiras, na "França-deverdade”. Só pode falar o francês, mas também vive o árabe e, no caso de Derrida, o iídiche, línguas do outro, mas que também são a sua, ainda que não as domine, porque é pela intermediação delas que pode viver o dia a dia. Essas reviravoltas envolvendo línguas nacionais, sistemas específicos, servem de entrada a uma reflexão sobre a linguagem (ao largo de), sobre a escritura: todo ato de comunicação é, em simultâneo, próprio e alheio, visto que movimentamos os signos que nos são caros, mas estes se atravessam por rastros de fora. Longe de uma reedição, agora idílica, de certa Babel, essa condição acaba por recair no jogo de certa violência, quando aspectos da língua tentam recalcar seus rastros, seus exteriores. Há sempre um esforço de tomada: "Porque não há propriedade natural da língua, esta não dá lugar senão à raiva apropriadora, ao ciúme sem apropriação. [...] A língua fala este ciúme, a língua não é senão ciúme à solta [...]" (DERRIDA, 2016, p. 51, grifo nosso).

Esse trecho nos detém e nos retém, nos faz pensar no modo pelo qual esse lugar indeciso da pertença da linguagem influi sobre ela mesma. Quando fala desse ciúme, quer dizer de uma força de imposição que é desejosa de restaurar a propriedade bem ali onde a aberração de sua existência foi declarada. $\mathrm{Na}$ esteira dessas reflexões, em entrevista sobre $\mathbf{O}$ monolinguismo do outro, Derrida (2005) tensiona seu caso em relação ao de Paul Celan, poeta romeno que escrevia em alemão, língua dos pais mortos durante o Holocausto. Essa operação, da escrita em outra língua, sua-do-outro, reaviva no filósofo a constatação de que esse processo apenas encena um teatro da impropriedade mais profundo, da própria estruturalidade da enunciação: 
É da essência da linguagem que a linguagem não se dê à apropriação. A linguagem é precisamente o que não se dá à possessão mas, por essa razão mesmo, provoca todos os tipos de movimento de apropriação. Porque a linguagem pode ser desejada mas não apropriada, dá a partida em toda sorte de gestos de posse e apropriação [...] (DERRIDA, 2005, p. 101). ${ }^{1}$

$* * *$

De volta ao monolinguismo, leiamos uma cena descrita por Derrida, no que ela deixa claro esse processo de tomada da propriedade justo onde ela não está - e como isso se relaciona a uma política e poética. É como uma fábula, reencenação de uma verdade histórica: em uma situação entre dono e escravo, o primeiro mantém suas relações de poder com o segundo por meio de uma simulação da propriedade - que, afinal, não é garantida por nada que não ela mesma. "Porque, contrariamente ao que a maior parte das vezes se é tentado a crer, o amo e senhor não é nada. E não tem nada de próprio. Porque o amo e senhor não possui como próprio, naturalmente, aquilo a que, no entanto, ele chama sua língua [...]" (DERRIDA, 2016, p. 50, grifo nosso) - e, da ausência essencial de um direito de propriedade mais amplo, logo se passa para essa negação da propriedade linguística. Com isso, pode-se ler que a propriedade não se afirma - bem como não se derrota - se não pela sua performance na língua: "Basta-lhe fazer-se ouvir, por qualquer meio que seja, basta pôr em marcha o seu 'speech act', criar as condições para isso, para lograr ser 'feliz' [...] e a partida está ganha, uma primeira ronda em todo caso estará ganha [...]” (DERRIDA, 2016, p. 50, grifo do autor).

\footnotetext{
$1 \quad$ No original: "It is of the essence of language that language does not let itself be appropriated. Language is precisely what does not let itself be possessed but, for this very reason, provokes all kinds of movements of appropriation. Because language can be desired but not appropriated, it sets into motion all sorts of gestures of ownership and appropriation [...]".
} 
A essa primeira rodada da disputa proprietária se segue a necessidade (a inevitabilidade mesmo) de uma seguinte, a revanche do possuído, que detonará os mecanismos retóricos a partir deles mesmos: "Libertará da primeira [atribuição de posse] confirmando uma herança ao interiorizá-la, ao reapropriar-se dela - mas apenas até um certo ponto, porque é a minha hipótese, não há nunca apropriação ou reapropriação absoluta [...]" (DERRIDA, 2016, p. 51). A propriedade, aquela do senhor, caduca com sua tomada - sua apropriação - por parte do subjugado. Mas, se caduca por ser herdada, permanece em jogo ainda.

Se a ideia é de que não há propriedade, aí vê-se que só há propriedades - e não há nunca apropriação absoluta. O que essa conclusão afasta é um entendimento triunfante dessa - de toda - reapropriação. Se em tal cena ela aparece como retorno do excluído, há de se pensar se não é pelo mesmo processo que o amo e senhor instituem seus poderes de posse pregressos (já que não poderíamos falar de "original”) - e não impede que após tal libertação não se sucederiam rounds outros, insurgências de novos atos de fala, outros, desejos de restaurar as antigas propriedades, ou até mesmo outras, novas. Menos que a afirmação de liberdade irrestrita da linguagem, o que se vê é um processo de posses instáveis; mas posses, ainda assim.

A noção capaz de dar conta dessa violência perpétua seria a "ex-apropriação" (DERRIDA, 2016, p. 51): o hífen entre a condição pretérita e o gesto de tomar posse encapsulam as revoluções internas e constantes a todo gesto que arrogue "tornar seu" o material linguístico de outro. 
Pois é impossível tomar de todo, como seu, o discurso do outro, ao passo que é impossível constituir uma fala pura, sem a presença do traço alheio. Como coloca Fernanda Bernardo (2011, p. 255), é a condição da língua mesma que a condena a ser outra - ainda que não possa deixar de ser a mesma:

Por outro e ipso facto, dir-se-á, a situação de Eco desenha também a cena da despossessão originária da língua ou daquilo a que, em o Monolinguismo do Outro, Derrida chamará "alienação originária", uma "alienação sem alienação" (e alienação sem alienação porque, no fundo, ela não aliena nada de próprio ou como tal) que institui toda a língua como língua do outro [...] (BERNARDO, 2011, p. 255, grifo da autora).

Que seu apontamento se dê em um texto que sonda o mito de Eco - tão caro a Derrida - ajuda-nos a entender algumas coisas. Recontar a história de Eco é dizer dessa ninfa amaldiçoada pelos deuses, condenada a só poder falar repetindo as últimas palavras que ouviu. Com a limitação se acostuma e toma como estratégia aprender a conversar a partir da reiteração - modo como irá causar a perdição de Narciso. É a "cena de uma desposessão originária", imagem de que a língua não pertence, mas existe - e insiste. Nos impõe uma necessidade de comunicação, impele a uma tomada de sua posse.

Entende-se, assim, que toda escrita seria uma eco-grafia: a inscrição de uma repetição, de uma herança (cf. BERNARDO, 2011). Inscrever e grafar os rastos de outrem é manipulálos, e tal manipulação, como tentamos demonstrar com essa história/estória, é sempre a imposição "político-fantasmática" (DERRIDA, 2016, p. 50) de uma marca de posse. Isso seria a ex-apropriação: o processo contínuo de usar a língua entre a despossessão e a tomada de propriedade que a acompanha. Uma 
não pode vir acompanhada/separada da outra, e essa relação só se prova na própria grafia, contaminada de ciúme, possuída por fantasmas; diz Derrida (2005, p. 99): “[...] o que eu sugiro é precisamente que não se pode apropriar uma linguagem, mas sim se engajar em um corpo a corpo, um combate com ela [...]". ${ }^{2}$

Esta noção de ex-apropriação nos interessa por iluminar certas ordens de combate. É não apenas esse corpo a corpo do inscritor contra a linguagem alheia, mas também um corpo a corpo que se segue no interior da própria escrita: entre as linguagens, sempre alheias, que se atravessam nela; entre as forças de estabilização da propriedade e a deriva de desapropriação que segue. Daí que a apropriação não é imitação, tão somente, cópia ou citação. Ela se dá nessa cena de ciúmes como ex-apropriação; e o termo nos é caro porque encaminha o problema dessa possessão de uma língua alheia nos termos da propriedade. Apropriar seria, em um nível mais profundo do que apenas tomar de empréstimo citações, termos, expressões, etc., o ato de tomar o lugar de posse daqueles signos, falar no lugar de. Mas que lugar é esse, se não podemos mais nem falar do espaço entre o meu e o do outro - afinal, não haveria uma "propriedade natural"?

\section{Do entre-lugar: escrever contra, escrever escrituras fal-} sas

Em um segundo momento da reflexão, de volta àquele hífen, pensemos nesse espaço no qual se situa a apropriação. $\mathrm{O}$ tão singelo sinal gráfico parece então representar esse estranho

2 No original: "[...] what I suggest is precisely that one never appropriates a language, but rather to carry on a hand-to-hand, bodily struggle with it $[\ldots] "$. 
espaço da ex-apropriação. Falemos dele sob a lógica do entrelugar, em uma retomada também do pensamento de Silviano Santiago, artífice derridiano das escritas nos trópicos.

O termo aparece no clássico ensaio $\mathrm{O}$ entre-lugar do discurso latino-americano (SANTIAGO, 2019), escrito em 1971 e que reflete sobre a relação da cultura latina com suas propostas éticoestéticas de assimilação do colonizador. Partindo da antropofagia como dinâmica, tanto da cultura letrada do movimento modernista como das práticas ritualísticas dos indígenas brasileiro, Santiago imagina a contribuição do latino como sendo a de contaminar as ideias colonizadoras, relacionadas a paradigmas de pureza e unicidade. Desde seu princípio, a cultura latina se vê invadida pelos signos do alheio, com os quais precisa aprender a lidar, em face da própria dominação. Entre a reverência que tomaria tais signos do colonizador como verdades e a rejeição isolacionista, o escrito latino opta pela brincadeira, dado que "as palavras do outro têm a particularidade de se apresentarem como objetos que fascinam seus olhos, seus dedos, e a escritura do texto segundo é em parte a história de uma experiência sensual com o signo estrangeiro [...]" (SANTIAGO, 2019, p. 33). Mas não é uma brincadeira inocente, assim como também não implica na aceitação. É uma disputa no centro da produção discursiva, como bem destaca Santiago (2019, p. 29): "Falar, escrever, significa: falar contra, escrever contra $[\ldots]$ "..

Como o franco-magrebino descrito por Derrida, o latino não possui senão os signos do outro para falar; mas eles não são seus. Não pode falar senão com uma multiplicidade de signos, ainda que não detenha nenhum. O que ele opera é uma positivação dessa pobreza ao tomar as armas do inimigo contra ele próprio. Se nada tenho, tudo possa usar - para logo abandonar em 
seguida, em favor de outros signos, mais adequados à situação. Essa dubiedade no exercício cultural é o que constitui, para essas escritas, um entre-lugar:

Entre o sacrifício e o jogo, entre a prisão e a transgressão, entre a submissão ao código e a agressão, entre a obediência e a rebelião, entre a assimilação e a expressão, - ali, nesse lugar aparentemente vazio, seu templo e seu lugar de clandestinidade, ali, se realiza o ritual antropófago da literatura latino-americana [...] (SANTIAGO, 2019, p. 37).

Há que se destacar aí, na ritmicidade da recorrência deste "entre", que ele compõe espaço, constitui esse lugar que é só aparentemente vazio, mas que, em verdade, é o templo onde se podem realizar as escrituras entrecruzadas por esses apelos de diferentes culturas, de diferentes línguas. É um lugar atravessado por aquele ciúme derridiano, é o espaço daquele nosso hífen de início, que interpõe uma distância entre desapropriação e apropriação; entre tirar do outro e apresentar como seu é que tudo se passa. $\mathrm{O}$ ex-apropriador se desenha com as cores do escritor latino, na medida em que ele também só se manifesta de modo clandestino, fugidio.

Podemos avançar nessa perspectiva ao pensar um texto filiado que Santiago escreve quando da maioridade de O entrelugar.... Em 1989, publica o ensaio As escrituras falsas são..., em que reflete sobre as mudanças pelas quais a prática antropofágica teria passado ao longo do século XX. De uma espécie de embate maior entre nacional e internacional que marcava aquela reflexão, a literatura parecia ter passado a uma máquina de guerras miniaturizadas, conflitos menores da ordem do cotidiano, contra uma difusão de invasões do estrangeiro sobre si. As disputas se miniaturizam - e passam a enfocar, cada vez mais, a questão da 
detenção do texto como centro de interesse. Segundo percebe, o apropriador pós-1980:

Quer desterritorializar o territorializado pelo seu gesto de transgressão à cerca de arame farpado que guarda a propriedade alheia. Ele levanta antes de mais nada a lebre do "sentido" da propriedade ficcional (assim como o historiador de hoje levanta a lebre do "sentido" da história). "Sentido" é direção e significado (embora possa ser também uma posição conhecida pela imobilidade obediente, no jargão militar e - por que não? - na crítica stalinista). Na direção em que caminha a propriedade caminha a história do seu significado hoje. Tanto direção quanto significado indicam (daí o sentido de "sentido") o que o próprio é o impróprio. (SANTIAGO, 1989, p. 307).

Essa caracterização se reenquadra no interesse pela propriedade: a apropriação é um gesto em direção à "cerca" da propriedade do alheio. Ao cortarem os arames, fazem vazar o "sentido" contido lá. E como se desmonta a cerca? Pela apresentação de uma obra apropriacionista, que Santiago define como "escrituras falsas de propriedade" (SANTIAGO, 1989, p. 307, grifo nosso). O termo é preciso, no que sabe expressar a indecidibilidade fundamental aos atos de apropriação - de exapropriação, portanto.

A reescrita, querendo-se escritura falsa de propriedade, faz pensar em uma tentativa de desapropriar sem apropriar. É uma escritura de propriedade em nome do apropriador que retira do posseiro anterior os direitos daqueles signos em questão. Mas é uma escritura falsa, pois este que toma não seria o dono de facto daqueles signos que está desapropriando por meio de tal papel. O termo faz pensar na artificialidade de toda e qualquer assunção de posse; mas "falsa", ali, é um adjetivo colado a um substantivo com o qual não parece concordar. São, não obstante, escrituras, 
forças de lei que acabam por atribuir posses, inequivocadamente. Muito próximas do debate derridiano, estas ideias poderiam complementá-lo: se, por um lado, não há propriedade absoluta, por outro, isso não quer dizer que há uma contínua disponibilidade. Quer dizer que só há contínuas desapropriações - e isto é entender que o desapropriado se cristaliza numa nova cerca de propriedade, para então ser alienado uma vez mais.

Isso está, também, em Santiago (1989), ao entender que a escritura de propriedade é uma letra de lei, que marca o apropriacionismo e fornece as bases para a sua análise. Ele, afinal, vale o quanto pesa:

De posse de escrituras falsas o escritor procura reconduzir a propriedade alheia por novos e altamente suspeitos caminhos de liberação, até que, por sua vez, as abandona de novo. O escritor sem-terra, ao contrário do tradicional ainda que moderno, já entra para o literário sabendo de antemão que não existe "sentido" definitivo no título de propriedade. A escritura (de um livro, de uma terra, etc) vale o tempo, o espaço e a força de uma assinatura, ou seja, a sua rentabilidade [...] (SANTIAGO, 1989, p. 308, grifo nosso).

\section{$* * *$}

Se a propriedade natural no domínio dos signos não existe, como falar então das suas consequências inegáveis na escrita? Abordando as formas como ela se impõe pelo ato de apropriação. No caso de Derrida (e aqueles que usa como ilustrações, como Paul Celan), a impressão proprietária é visível na sua relação (franco-magrebina) com o francês: alheio, mas o qual ele precisa tomar, mesmo que essa tomada não se dê de todo. $\mathrm{O}$ espaço que a propriedade ocupa é um entre-lugar, entre a impossibilidade essencial de ter a língua e a necessária utilização desta para se exprimir - para existir. É o entre-lugar interposto de "não falo 
senão uma única língua, que não é minha" a "não se fala nunca apenas uma única língua".

Falar de ex-apropriação, portanto, é falar desse jogo; ao tomarmos esse conceito, nós o fazemos aproximando-o da ideia de grilagem. Essa figura ganha força pela leitura de Santiago e pela observação do modo como opera, como imagem dessa exapropriação da qual tentamos nos acercar. Grilar é apresentar um documento falso que reclama a posse de algo para si, uma posse que não está lá, que não seria de direito. Mas isso é também demonstrar que não há propriedade de direito, na medida em que ela se afirmaria tão somente por documentos - todos tão potencialmente falsos quanto os do grileiro. Isso seria o "levantar a lebre do sentido da propriedade": demonstrar sua instabilidade. Mas a demonstração só se dá na escritura. A ex-apropriação, assim, se lê como nome dessa operação de grilagem da língua.

Sob tal luz é que também se pode ir compreendendo o espaço que ocupam essas intervenções "autorais", à medida que a intervenção de propriedade atua no funcionamento da própria herança (nesses textos, herança tanto do texto apropriado quanto da própria história da apropriação):

Herdar não é apenas receber passivamente algo que já está aqui, como uma tomada de posse. Herdar é reafirmar, pela transformação, mudança e desvio [...] Uma herança deve ser assinada; deve ser contrassinada - isto é dizer, no fundo, que se deve deixar a assinatura na linguagem mesmo, na linguagem que recebe-se [...] (DERRIDA, 2005, p. 104). ${ }^{3}$

Fala-se em assinatura, também, a respeito da marca ao pé de um documento que, ao mesmo tempo, garante a propriedade

3 No original: "But to inherit is not simply to receive passively something that is already there, like a possession. To inherit is to reaffirm through transformation, change, and displacement. [...] An inheritance must be signed; it must be countersigned — that is to say, at bottom, one must leave one's signature on inheritance itself, on the language that one receives [...]". 
e evidencia sua condição frágil. Assinatura como a de que falava Santiago (1989). Percebe-se como o escritor ex-apropriador sem-terra e sem-texto - lembra outras figuras críticas do autor, como a da literatura anfíbia (SANTIAGO, 2005), ou ainda a do alerta sobre a ameaça do lobisomem (SANTIAGO, 1998). Não se apropria para tornar-se o outro. Não é o caso de uma transformação; o que se mira são suas posses. O que queremos destacar aqui, em face disso, é como um pensamento sobre o lugar da propriedade oferece um ponto de vista heurístico ao problema da citação e da reescrita e como, diante das traduções interlinguísticas, internacionais, realça uma espécie de condição apátrida constitutiva da literatura. A nação só se entende como disseminação (cf. BABBHA, 1998). Essa condição apátrida não insiste como tal, porém, já que a todo momento tenta tomar para si os passaportes de outrem. É nas suas escrituras, falsas, que apresenta uma forma de grilar a propriedade daquilo que não tem - uma voz, uma língua, um país.

Escrituras falsas, de contrassinaturas igualmente fictícias, utilizadas como vistos e passaportes ilusórios, para fazer passar o seu como do outro - e demonstrar como mesmo o do outro não é dele, já que se oferece assim para a apropriação. Como se apresentam esses textos, registros poéticos do corpo a corpo com a despossessão? A ex-apropriação só vale quanto pesa e deve ser explorada no cálculo da rentabilidade de tais escritos.

\section{Línguas bífidas: escrituras de ex-apropriação}

Exploremos os limites mesmo desse lugar latino, no que se avizinha ao inimigo e se recusa a acabar. Leiamos como passaporte falso os textos de Gloria Anzaldúa, escritora mexicana 
nascida no Texas que, em Borderlands/La frontera (1987), erige um monumento ao axioma de sua condição linguística.

How to tame a wild tongue ("Como domar uma língua selvagem"), Anzaldúa (1987) pergunta, a perceber uma persistência do espanhol a tomar sua fala. Mas não é o seu espanhol, apenas herdado, opacamente, de sua abuela e de outros parentes. Assim como não é seu o inglês, como é constantemente relembrada: pelos outros, na zombaria do sotaque, ou por si mesma, pelas irrupções abruptas das expressões chicanas. A solução acaba por ser assumir essa variação, conceber uma poética que encarna essa possessão do espanhol chicano - dupla possessão, pois o inglês é também tomado, e não natural:

For a people who cannot entirely identify with either standard (formal, Castillian) Spanish nor standard English, what recourse is left to them but to create their own language? A language which they can connect their identity to, one capable of communicating the realities and values true to themselves-a language with terms that are neither español ni ingles, but both. We speak a patois, a forked tongue, a variation of two languages [...] (ANZÁLDUA, 1987, p. 63). ${ }^{4}$

Falar em uma língua bífida: a imagem dessa partição do aparelho fônico ecoando o espaço de infinitas bifurcações que é o entre-lugar do ex-apropriador. Interessa também, na construção da perspectiva de pesquisa deste artigo, perceber aí a dinâmica semiótica de apropriação desses escritos, bem como na proposição de contrapor o imperialismo do inglês por um "terrorismo linguístico" (ANZÁLDUA, 1987, p. 58), na mescla deliberada de dialetos e sotaques, criando um espaço de

\footnotetext{
4 No caso das citações poéticas de Anzáldua, tanto quanto as de Glissant, optaremos por manter o texto original, sem tradução. Se nosso foco é compreender a força de tais textos como manifestações plurilinguísticas de seu entre-lugar, não pareceria adequado conformá-los a uma rápida transposição ao português, língua com a qual nenhuma das duas poéticas relaciona-se diretamente.
} 
conflito, encarnação concreta de uma impossibilidade de situar a "verdadeira" propriedade das línguas nacionais. E essa indecisão, muito longe de ser mero preciosismo conceitual, se imprime sobre a língua, concreta em carne, dos sujeitos, eles próprios tornados "improprietários", ou mesmo tornados impróprios, se pensarmos no sofrimento causado a Anzáldua por seu desterro linguístico - mas também talvez posseiros, grileiros de uma força outra, manipulável nesses espaços vazios dos territórios demarcados da língua. Lemos isso em trechos como este:

Deslenguadas. Somos los del español deficiente. We are your linguistic nightmare, your linguistic aberration, your linguistic mestisaje, the subject of your burla. Because we speak with tongues of fire we are culturally crucified. Racially, culturally and linguistically somos huerfanos - we speak an orphan tongue [...] (ANZALDÚA, 1987, p. 58).

Vemos aí a expressão do falar com-e-contra do entre-lugar, dado que ex-apropria as linguagens alheias como estratégia de ação da própria poética, para virar o jogo da opressão. É em termos muito semelhantes que operam outras dessas escrituras falsas, aquelas pensadas e operadas por Édouard Glissant, poeta e teórico antilhano.

É especialmente importante a ideia de crioulização, apresentada por Glissant, processo de transformação pelo qual a linguagem dos povos escravizados e/ou migrantes mistura-se àquela de seus proclamados senhores, gerando uma língua de detenção irrastreável - bífida. "E o que é uma língua crioula? É uma língua compósita, nascida do contato entre elementos linguísticos absolutamente heterogêneos uns aos outros. [...] $\mathrm{O}$ que chamo de língua crioula é uma língua cujos elementos constituintes são heterogêneos uns aos outros [...]” (GLISSANT, 
2005, p. 24).

Em que circunstâncias se dá esse processo de crioulização? Para chegar a ele, Glissant (1989) retoma uma ideia de despossessão originária no contexto do Caribe. Despossessão cultural dos escravos desenraizados da África, mas também despossessão econômica do sistema das plantations, calcado em escambos - e essa dupla pauperização, que iguala como originariamente espoliados tanto os servos quanto os senhores, reforça a ilusão do ter. Essa impossibilidade de pertença se traduz, forçosamente, no fazer poético - no corpo a corpo. O poeta crioulo é aquele que sabe da impossibilidade da propriedade - não apenas da propriedade semiótica da linguagem, mas de qualquer uma, no seu Caribe-colônia - e precisa saber inscrever essa despossessão. Como explicam estas belas linhas de Glissant:

O que quero dizer é que deporto e desarrumo minha língua, não elaborando sínteses, mas sim através de aberturas linguísticas que me permitem conceber as relações das línguas entre si em nossos dias, na superfície da terra - relações de dominação, de convivência, de absorção, de opressão, de erosão, de tangências, etc. -, como em um imenso drama, em uma imensa tragédia de que minha própria língua não pode ficar isenta e salva [...] (GLISSANT, 2005, p. 49-50).

Se a língua não pode ficar isenta dessas consequências da despossessão - sua força de migração compulsória e contínua -, Glissant aposta em tornar o caráter deportado de sua linguagem sua principal força. Se seus textos são menos explicitamente marcados pelo trânsito, em comparação com Anzáldua, aqui e ali aparecem expressões do crioulo; em outros momentos, há o francês. O francês "verdadeiro"? Certamente que não, e é essa sua função em tal poética da relação. Comparecer como que puro, mas permanecendo em cena o bastante para dar a ver 
algumas rachaduras. Enquanto estratégia de ex-apropriação, o alheio é reapresentado para que possamos ver nele tanto as marcas dos usos pretéritos quanto a impostura do uso presente, nenhum deles mais "de direito" que outro. Ambos convivem, palimpsesticamente, no corpo do poema, entendido como uma espécie de tradução dessa mesma impropriedade: "O que isso significa, senão que o tradutor inventa uma linguagem necessária de uma língua para a outra, assim como o poeta inventa uma linguagem em sua própria língua?"' (GLISSANT, 2005, p. 56).

Tradução do impróprio e do entre, como podemos encaminhar, ao lermos um poema chamado, é preciso frisar, Poétique, presente no livro Le grand chaos (2000):

\author{
Comprendre temps chaleur \\ Roche chaleur \\ douleur mariee \\ cri vaporant son mot \\ voyelle a voyelle \\ concretees \\ $[\ldots]$ \\ (GLISSANT, 2000, p. 162). ${ }^{5}$
}

Que da rocha, do calor antilhano, evaporem as vogais, material (concreto) da produção poética, isso é encenar o entrelugar. Que Glissant, negro e descendente de escravos, construa suas encenações por meio da língua do outro, isso é sinal, é seu combate de ex-apropriação. Que ambos os gestos se aliem nas linhas de um poema, parece-nos suas potências.

\title{
Considerações finais
}

De volta ao que escreveu Glissant sobre sua poética da relação, retomemos a ideia do escrever por meio da ex-

\footnotetext{
$\overline{5}$ Tradução: "Compreender o tempo quente / Rocha quente / dor casada / grita vaporosa sua palavra / vogal a vogal / concretas".
} 
apropriação, no entre-lugar, como um "imenso drama", uma imensa tragédia da qual a língua não se salva - pois ocorre, sobretudo, nos palcos da língua. Essa citação, em um argumento circular, nos leva a outra, que nos permite retomar Derrida e encaminhar algumas conclusões.

Em uma de suas últimas entrevistas dadas em vida, o filósofo se permitiu uma reflexão sintética de suas discussões sobre a língua. "Uma história singular exacerbou em mim essa lei universal: uma linguagem não é algo que pertence. Não de forma natural e em sua essência. Daí os fantasmas da propriedade, apropriação e imposição colonialista [...]" (DERRIDA, 2007, p. 38). ${ }^{6}$

Essa história é a que tentamos expor aqui, expressa em alguns gestos de apropriação. É o conto de uma impossibilidade originária de ter posse da linguagem: ela sempre está além. Ou aquém: só se detém num entre-lugar. A propriedade se equilibra nesse delicado hífen: se não se pode ter a língua, essa é a deixa para a todo momento se tentar tomá-la. Mas ela foge uma vez mais e cabe à responsável pelo o manuseio da língua - a literatura - saber lidar com essa estranha herança.

Com base nisso, futuras pesquisas teriam como objetivo responder às seguintes perguntas: como contar a história dessa lei, como se consolida a impropriedade constitutiva? E, mais, como se contam estórias a partir dela - como a inevitável apropriação cria suas escrituras falsas, o que escreve a partir disso?

6 No original: "A singular history has exacerbated in me this universal law: a language is not something that belongs. Not naturally and in its essence. Whence the phantasms of property, appropriation, and colonialist imposition [...]". 
Referências

ANZALDÚA, Gloria. Borderlands/La Frontera: The New Mestiza. San Francisco: Aunt Lute Books, 1987.

BHABHA, Homi. O local da cultura. Belo Horizonte: Ed. UFMG, 1998.

DERRIDA, Jacques. Learning to live finally: an interview with Jean Birnbaum. Nova York: Melville House, 2007.

DERRIDA, Jacques. O monolinguismo do outro ou a prótese de origem. Tradução de Fernanda Bernardo. Belo Horizonte: Chão da Feira, 2016.

DERRIDA, Jacques. Sovereignties in question: the poetics of Paul Celan. Nova York: Fordham University Press, 2005.

GLISSANT, Édouard. Caribbean discourse: selected essays. Charlottesville: UP of Virginia, 1989.

GLISSANT, Édouard. Introdução a uma poética da diversidade. Juiz de Fora: Editora UFJF, 2005.

GLISSANT, Édouard. Pays rêvé, pays réel. Paris: Gallimard, 2000.

SANTIAGO, Silviano. 35 ensaios de Silviano Santiago. São Paulo: Companhia das Letras, 2019.

SANTIAGO, Silviano. A ameaça do lobisomem. Revista Brasileira de Literatura Comparada, Florianópolis, 1998. p. 31-44.

SANTIAGO, Silviano. As escrituras falsas são. Revista 34 Letras, Rio de Janeiro: Editora 34, n. 5-6, p. 307-308, set. 1989. SANTIAGO, Silviano. O cosmopolitismo do pobre. Belo Horizonte: UFMG, 2005. 